Dermatology 2009;219:184-186

DOI: $10.1159 / 000228327$

\section{Treatment of Pigmented Purpuric Dermatosis with Topical Photodynamic Therapy}

\section{Sue Kyung Kim, Eun Hyung Kim, You Chan Kim}

Department of Dermatology, Ajou University School of Medicine, Suwon, Korea

Key Words

Photodynamic therapy $\cdot$ Pigmented purpuric dermatosis

\section{Introduction}

The pigmented purpuric dermatosis (PPD) is an all-encompassing term that refers to a group of cutaneous lesions that have in common petechiae and bronze discoloration of the skin with primary localization to the legs. The histopathological features include superficial lymphocytic infiltration with hemorrhage [1]. It may resolve spontaneously but tends to follow a prolonged course over months to years. The treatment has been unsatisfactory with limited benefit from topical or systemic steroids, griseofulvin and psoralen plus ultraviolet A [2]. We report 2 cases of PPD that improved with photodynamic therapy (PDT).

\section{Case Reports}

A 32-year-old woman presented with a $1.5 \times 3 \mathrm{~cm}$ brownish patch with multiple punctuated macular purpuric spots on the leg that had initially been noted 5 years previously. She had no drug history and showed no other symptoms of varicose veins and chronic venous insufficiency such as leg swelling, leg achiness and leg tension. The histopathological examination revealed superficial dense lichenoid lymphocytic infiltration with red blood cell extravasation and hemosiderin deposits. Mild telangiectasia was also noticed. The findings of the routine laboratory studies, including markers for hepatitis, were within normal limits. In spite of the various treatments including topical steroids and triamcinolone intralesional injections for several years, there was little change in the lesion. We attempted to treat the lesion with 5-aminolevulinic acid (ALA) in combination with intense pulse light (IPL). Twenty percent topical ALA (Medac, Hamburg, Germany), in a petrolatum vehicle, was applied to the lesion and covered with an occlusive polyurethane film (Tegaderm; 3M, St. Paul, Minn., USA). After $3 \mathrm{~h}$, the lesion was irradiated with IPL (Lumenis One; Lumenis Corporation, Santa Clara, Calif., USA, with fluences of $18-20 \mathrm{~J} / \mathrm{cm}^{2}$, at 3 -week intervals). At each subsequent treatment the fluence was increased by $1 \mathrm{~J} / \mathrm{cm}^{2}$ according to the results of the previous treatment. Energy was delivered in double-pulse trains of $3.5 \mathrm{~ms}$ with pulse delays of $20 \mathrm{~ms}$. Cut-off filters of
$590 \mathrm{~nm}$ were used. The patient did not complain about pain and burning sensation during the treatment. After 3 sessions, the lesion showed clinical improvement other than postinflammatory hyperpigmentation. However, the patient had to discontinue treatment because hemorrhoid surgery was planned.

A 40 -year-old woman presented with a $3 \times 4 \mathrm{~cm}$ brownish patch that had first been noted 3 years previously. She had no drug history and showed no other symptoms of varicose veins and chronic venous insufficiency. The histopathological examination was consistent with the diagnosis of PPD. The findings of the routine laboratory tests were in the normal range. We attempted to treat the lesion with PDT and topical methyl-ALA (Metvix ${ }^{\circledR}$, Galderma, France). The occlusive dressing method was identical to the previous case. The lesion was illuminated with red light from a Waldman PDT 1200 lamp, at a light dose of $15 \mathrm{~J} / \mathrm{cm}^{2}$ and a fluence rate of $50 \mathrm{~mW} / \mathrm{cm}^{2}$. The patient did not feel pain and burning sensation during the treatment. After 7 treatment sessions, the lesion showed clinical improvement, and we performed a second biopsy. The histopathology revealed decreased lymphocytic infiltration in the upper dermis and red blood cell extravasation. In addition, the telangiectasia was improved. For the immunohistopathological studies, the positive cells for CD3, CD4, CD8, CD68 and CDla were decreased after the PDT. According to the staining against factor-VIII-related Ag, the vessel number and size were also decreased after the PDT. After 6 months, she had no recurrence but only slight postinflammatory hyperpigmentation around the treated lesion (fig. 1, 2).
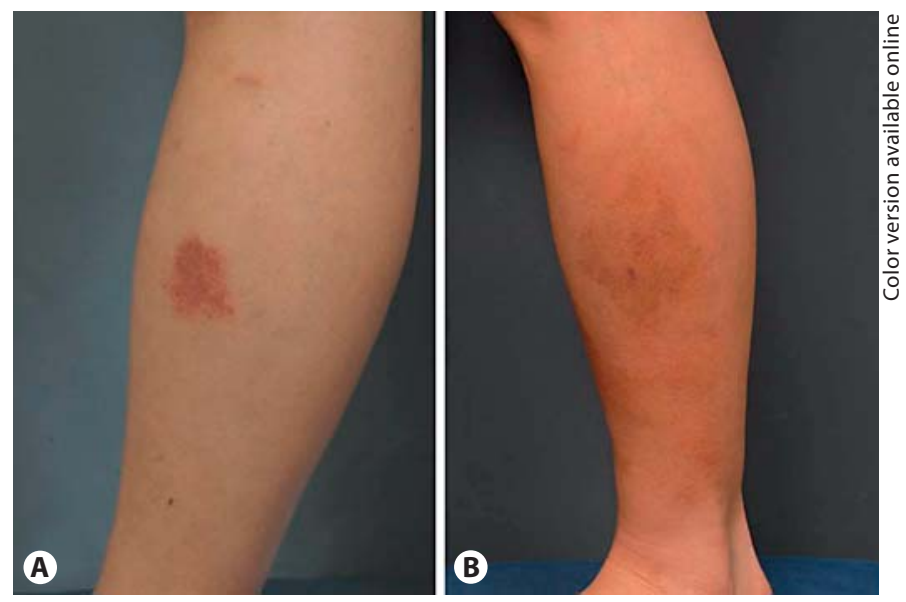

Fig. 1. A The brownish patch on the second patient's leg before treatment. B The same lesion after 7 sessions of PDT.

\section{KARGER}

(ㄷ) 2009 S. Karger AG, Basel

Fax +41613061234 E-Mail karger@karger.ch www.karger.com 

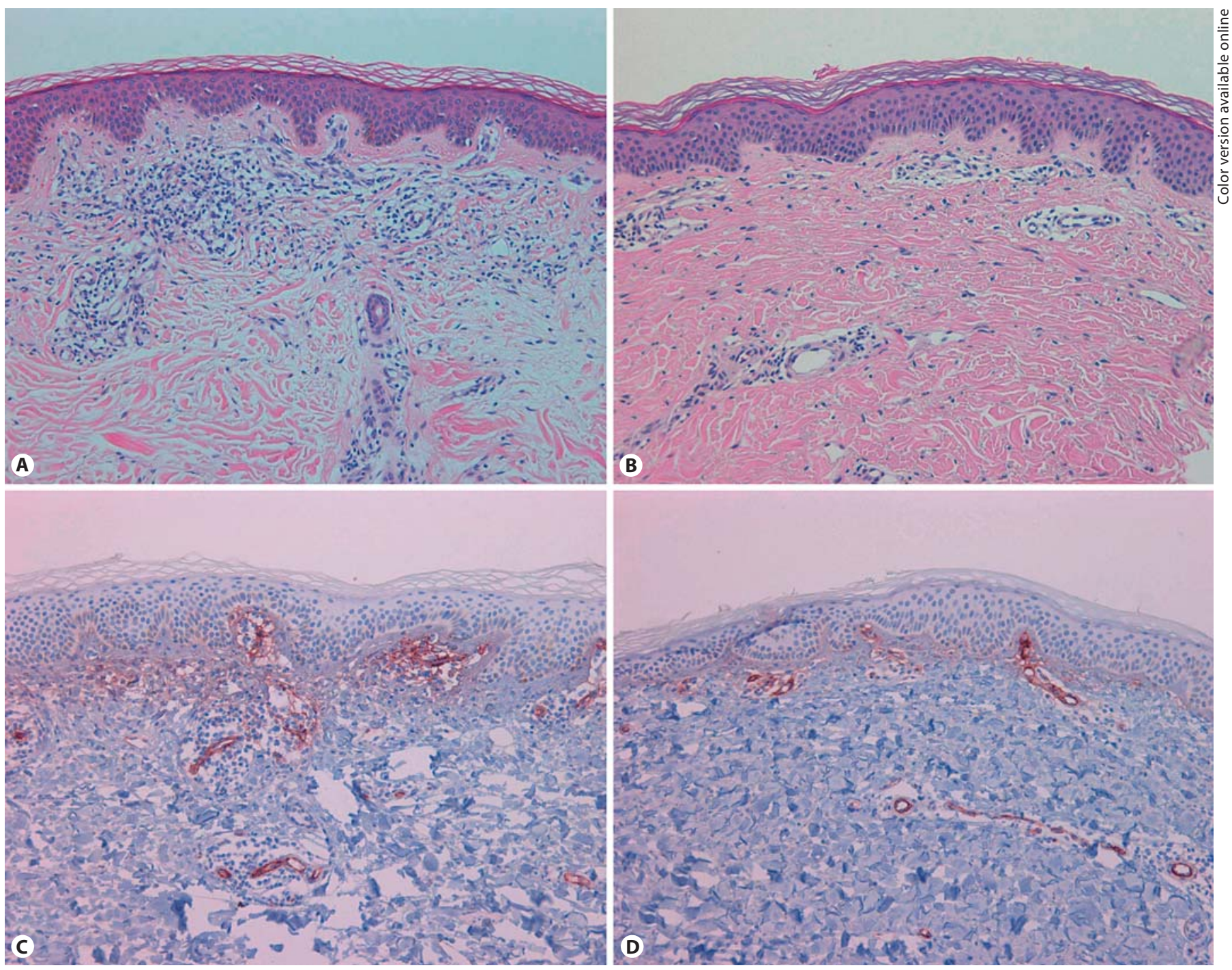

Fig. 2. Histopathologic findings of specimens from the second patient. A Dense lichenoid lymphocytic infiltration in the upper dermis with red blood cell extravasation and telangiectasia. HE. $\times 200$. B Decreased lymphocytic infiltration in the upper dermis

and red blood cell extravasation after PDT. HE. $\times 200$. C FactorVIII-related Ag-positive cells are noted in the vessels of the upper epidermis. $\times 200$. D Decreased number and size of vessels were noted after PDT. $\times 200$.

\section{Discussion}

The pathogenesis of PPD is unknown. There are 3 different proposed explanations about it: first, a disturbance or weakness of the blood vessels leading to capillary fragility and erythrocyte extravasation [3], second, the role of humoral immunity and third the role of cellular immunity [3]. The infiltrate in PPD consists of lymphocytes, macrophages and Langerhans cells, which may lead to vascular fragility and subsequent leakage of erythrocytes [3].

In the first patient an IPL was used in combination with topically applied ALA. Because IPLs are effective for the treatment of vascular disease and might also have a positive effect on PPD, we used red light as a light source in the second patient to evaluate the therapeutic efficacy of PDT only.

PDT is increasingly used in the treatment of various skin diseases. Pretreatment, such as curettage/debulking, tape stripping, microdermabrasion or laser ablation, of the hyperkeratotic skin lesion may improve the clinical outcome of PDT [4]. However, in the present cases, we did not need pretreatment because the lesions did not show hyperkeratosis. The main adverse effect of PDT is pain. Recently, it was suggested that the second treatment of PDT was significantly more painful than the first one [5]. However, our patients did not feel pain or burning sensation during several treatments.

Topical PDT has been proven to be a useful treatment for a variety of malignant skin tumors and inflammatory diseases. In contrast to PDT for tumors, where cellular destruction is the main 
goal of the therapy, the modulation of cell functions has been considered to be the main role of PDT in inflammatory skin conditions. Significantly lower doses of both light and photosensitizer are used in the context of a 'low-dose PDT' for the treatment of inflammatory skin conditions [6]. Depending on the variables, PDT can alter the balance between stimulation or regulation of the immune response by the release of certain cytokines, expression of heat shock proteins or the release of antigens from the treated tissue [7]. The effect of PDT on epidermal Langerhans cells and antigen-presenting cells such as dendritic cells and macrophages has been reported $[8,9]$. We also found a decreased number of positive cells for CD3, CD4, CD8, CD68 and CD1a after PDT in the second case.

The PDT showed therapeutic effects not only by immunomodulation but also by vascular destruction of the targeted lesion. Several studies have reported on the vascular effects of PDT [1012]. It has been suggested that topical PDT has a pronounced effect on the microcirculation. The photodynamic effects might not be mediated solely by porphyrins localized in the parenchyma but also by porphyrins in the microvasculature [11]. This mechanism might influence the vascular structure of PPD. We also found a decreased number and size of the vessels after PDT in our case. However, to confirm the vascular effects of PDT, further studies are needed with other diseases that manifest themselves with vascular lesions.

We report 2 patients with PPD that demonstrated a good response to PDT. PDT may be considered in cases of PPD where the lesion is localized and is recalcitrant to conventional therapy.

\section{References}

1 Magro CM, Schaefer JT, Crowson AN, Li J, Morrison C: Pigmented purpuric dermatosis: classification by phenotypic and molecular profiles. Am J Clin Pathol 2007;128:218-229.

-2 Basak PY, Ergin S: Should pentoxifylline be regarded as an effective treatment for Schamberg's disease? J Am Acad Dermatol 2001;44:548549.
3 Schroeder-Devere T: Pigmented purpuric dermatoses; in Wolff K, Goldsmith LA, Katz SI, Gilchrest BA, Paller AS, Leffell DJ (eds): Fitzpatrick's Dermatology in General Medicine. New York, McGraw-Hill, 2008, pp 1633-1636.

4 Gerritsen MJ, Smits T, Kleinpenning MM, van de Kerkhof PC, van Erp PE: Pretreatment to enhance protoporphyrin IX accumulation in photodynamic therapy. Dermatology 2009;218:193-202.

5 Lindeburg KE, Brogaard HM, Jemec GB: Pain and photodynamic therapy. Dermatology 2007;215:206-208.

6 6 Babilas P, Landthaler M, Szeimies RM: Photodynamic therapy in dermatology. Eur J Dermatol 2006;16:340-348.

7 Nowis D, Stokłosa T, Legat M, Issat T, Jakóbisiak M, Gołąb J: The influence of photodynamic therapy on the immune response. Photodiagn Photodyn Ther 2005;2:283-298.

$>8$ Gruner S, Meffert H, Volk HD, Grunow R, Jahn S: The influence of haematoporphyrin derivative and visible light on murine skin graft survival, epidermal Langerhans cells and stimulation of the allogeneic mixed leucocyte reaction. Scand J Immunol 1985;21:267-273.

9 Hryhorenko EA, Oseroff AR, Morgan J, Rittenhouse-Diakun K: Antigen-specific and -nonspecific modulation of the immune response by aminolevulinic-acid-based photodynamic therapy. Immunopharmacology 1998; 40:231-240.

10 Saw CL, Olivo M, Chin WW, Soo KC, Heng PW: Transport of hypericin across chick chorioallantoic membrane and photodynamic therapy vasculature assessment. Biol Pharm Bull 2005;28:1054-1060.

11 Schacht V, Szeimies RM, Abels C: Photodynamic therapy with 5-aminolevulinic acid induces distinct microcirculatory effects following systemic or topical application. Photochem Photobiol Sci 2006;5:452458.

12 Hammer-Wilson MJ, Akian L, Espinoza J, Kimel S, Berns MW: Photodynamic parameters in the chick chorioallantoic membrane (CAM) bioassay for topically applied photosensitizers. J Photochem Photobiol B 1999;53:44-52.

\section{You Chan Kim}

Department of Dermatology, Ajou University School of Medicine 5 Wonchon-Dong, Yeongtong-Gu

Suwon 443-721 (South Korea)

Tel. +82 31219 5190, Fax +82 31219 5189, E-Mail maychan@ajou.ac.kr 